\title{
In Memoriam: Asghar Aghamohammadi (May 30, 1951-November 14, 2020)
}

\author{
Nima Rezaei ${ }^{1,2}$
}

Received: 5 December 2020 / Accepted: 8 December 2020 / Published online: 4 January 2021

(C) The Author(s), under exclusive licence to Springer Science+Business Media, LLC part of Springer Nature 2021

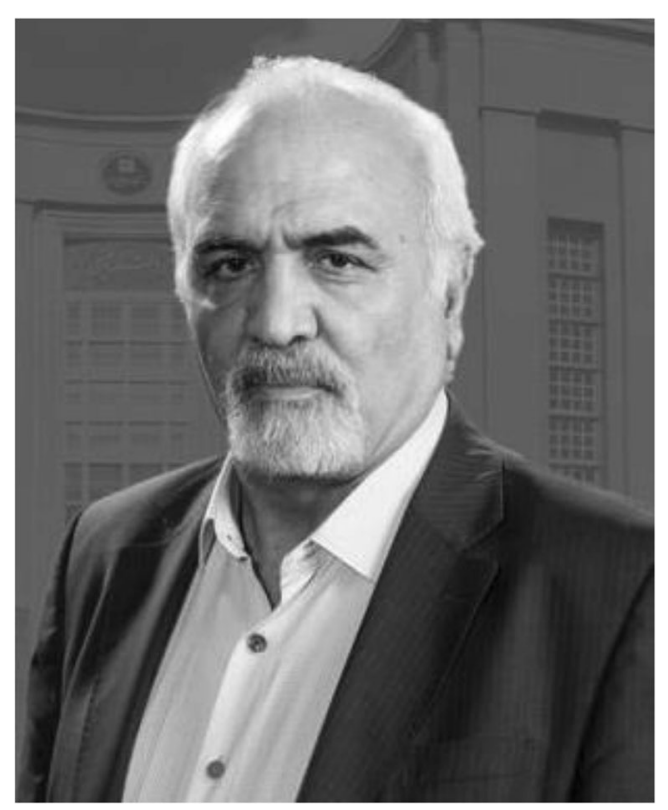

Asghar Aghamohammadi, who I can name as the father of primary immunodeficiency diseases (PID) in Iran, passed away on November 14, 2020, at the age of 69. He died in Tehran, the capital of Iran, where he dedicated his life to providing the best care for PID patients, as well as to facilitating research and education in this field. He was a full professor of clinical immunology and allergy and the Head of the Research Center for Immunodeficiencies (RCID) at Tehran University of Medical Sciences.

Nima Rezaei

rezaei_nima@tums.ac.ir; rezaei_nima@yahoo.com

1 Research Center for Immunodeficiency, Children's Medical Center, Tehran University of Medical Sciences, Tehran, Iran

2 Primary Immunodeficiency Diseases Network (PIDNet), Universal Scientific Education and Research Network (USERN), Tehran, Iran
The sad news of his death left us all in grieving shock, especially in view of the coronavirus disease (COVID-19) pandemic, which has already taken away many colleagues, friends, and loved ones. He dedicated his life to patients' care and research on PIDs until he was seriously affected with COVID-19 two weeks before his death. Although the disease was mild in the beginning, it turned to show its aggressive face, and together with the influence of underlying diseases, they lead to his multiorgan failure and death [1]. As always, his main concerns were patients with PID; one of his recent papers evaluated the impact of SARS-CoV-2 pandemic on patients with primary immunodeficiency, which demonstrated a higher mortality rate in PID [2], but, sadly, it seems that the pediatricians are more affected by COVID-19 than their pediatric patients [3].

Professor Aghamohammadi was born in 1951 in the Lashgarabad neighborhood of Ahvaz city, in Khouzestan Province, southwestern Iran. Together with his 3 other siblings, he started primary education in a middle-level elementary school, which was the beginning of a long journey for his inquisitive mind, when he made an effort to document his paternal pedigree for thirteen generations. After completing his primary education in Ahvaz, he moved to Mashhad, the capital city of Khorasan Razavi Province, to study medicine in 1971, and then moved to Jundishapur University of Ahvaz to be graduated as a medical doctor in 1978. After graduation, he served as the vice chancellor of medical care at the Red Crescent organization for 6 years, which was his first executive role during his services. Then, he continued his post-graduate education in pediatrics in 1984, followed by a fellowship in clinical immunology in 1988 . His enthusiasm for learning and serving patients was the motivation to spend a 3-year supplementary course in clinical immunology at Great Ormond Street Hospital, Institute of Child Health, in London. Gathering all these experiences and skills, he returned to Iran in 1995 to start his carrier as a faculty member in the Department of Pediatrics, Children's Medical Center, Tehran University of Medical Sciences [4].

During his career, he was committed to many executive responsibilities, which all of them were in the favor of patients' 
care. Upon his return to Iran, he had two main goals: to improve the "infrastructures" and "research" for PIDs in Iran. With this motivation, and together with his colleagues, he established the Iranian Primary Immunodeficiency Diseases Registry (IPIDR) in 1999, which was without a doubt one of his most valuable services for PID patients to more efficiently provide medical, social, psychological, and financial support for these patients [5]. As a medical student at that time, I was very pleased to help him establish the IPIDR as part of my medical thesis. Proudly, during the past 20 years, more than 3000 PID patients have been registered in this database, and the data were periodically published [6]. His second important effort was the establishment of the "Association for PID Patients Support" to serve as a charity for these patients. Moreover, he created a network to connect nearly 100 subspecialists in clinical immunology and allergy in Iran, aiming to promote the knowledge of general practitioners and pediatricians about PIDs. His other executive responsibilities included the head of Amirkabir Hospital at Tehran University of Medical Sciences, Vice Deputy of research in the Pediatric Department at Children's Medical Center, Tehran University of Medical Sciences. He also established the "Immunology and Genetics Journal" and did his best to build and develop the "J Project" in Iran and all over Eurasia. He was also an active member of the International Patient Organization for Primary Immunodeficiencies (IPOPI) and the European Society for Immunodeficiencies (ESID) and attended almost all PID scientific events, including the meetings organized by the Jeffrey Modell Foundation (JMF).

Starting as a junior faculty member and then becoming a top $1 \%$ scientist in clinical medicine, he dedicated his scientific life to basic and clinical research in PIDs. He believed that it is necessary to develop research interest in students, together with providing appropriate infrastructures and high-rank decisionmaking attitudes. In line with this belief, he established the Research Center for Immunodeficiencies (RCID) in 2010, and served as the Head of the RCID for the next 10 years. He also successfully organized annual meetings focusing on PIDs since 2005 . His scientific output included publishing nearly 400 papers through developing national and international collaborations with different countries, including the Departments of Clinical Immunology at Harvard Medical School in the USA, Karolinska Institute in Sweden, Brescia University in Italy, and University of Toyama in Japan. He studied the clinical aspects, as well as treatment and pathophysiology of PIDs, with special focus on antibody deficiencies, namely, X-linked agammaglobulinemia, common variable immunodeficiency, hyper IgM syndromes, and hyper IgE syndromes, and other types of PIDs. Importantly, one of his most valuable research products was the textbook "Primary Immunodeficiency Diseases: Definition, Diagnosis and Management" [7, 8]. He also did his best to prepare a practical guide for Inborn Errors of Immunity, which will be published in the spring of 2021 [9].
He was also a distinguished teacher, whose voice will be always remembered by his students. He trained and supported many students, who developed their own research interests, and joined the group of top $1 \%$ scientists. He believed that physicians should be trained in research as well and, therefore, was one of those who promoted the idea of training physician-scientists in Iran. His words on the student-professor relationship will always remain in our minds when he said: "if you devote your time to your students, teach them the way of critical thinking in addition to training, and respect their rights, your students will be your followers. The relationship of professor and student is like two mountaineers who reached several mountaintops together; then, the day will come when the professor may not proceed any longer, but will heartfully enjoy his students' promotion!" [4].

Professor Aghamohammadi was a true physician, whose patients will always remember him for his support, not only medically but also socially and financially. He was a dedicated researcher and scientist whose aim was to promote knowledge in support of PID patients and who established numerous scientific collaborations for this purpose. He was a compassionate teacher whose students will remember him for all the ideas and training he provided.

We shall not forget that this prominent scientist, who was also a family man spreading his love not only to his own family and children but also to his patients, students, friends, and colleagues. May his name be always remembered with respect and kindness.

\section{References}

1. TUMS. The funeral of Prof. Asghar Aghamohammadi. 2020. pr. tums.ac.ir/ZdDH.

2. Delavari S, Abolhassani H, Abolnezhadian F, Babaha F, Iranparast $\mathrm{S}$, Ahanchian $\mathrm{H}$, et al. Impact of SARS-CoV-2 pandemic on patients with primary immunodeficiency. J Clin Immunol. 2020.

3. Rezaei N. COVID-19 affects healthy pediatricians more than pediatric patients. Infect Control Hosp Epidemiol. 2020:1.

4. TUMS. Prof. Asghar Aghamohammadi: the one who doesn't know ethics shouldn't enter medicine. 2016. pr.tums.ac.ir/Z11n.

5. Aghamohammadi A, Moein M, Farhoudi A, Pourpak Z, Rezaei N, Abolmaali K, et al. Primary immunodeficiency in Iran: first report of the National Registry of PID in Children and Adults. J Clin Immunol. 2002;22(6):375-80.

6. Abolhassani H, Kiaee F, Tavakol M, Chavoshzadeh Z, Mahdaviani SA, Momen T, et al. Fourth update on the Iranian National Registry of Primary Immunodeficiencies: integration of molecular diagnosis. J Clin Immunol. 2018;38(7):816-32.

7. Rezaei N, Notarangelo LD, Aghamohammadi A. Primary immunodeficiency diseases. Springer; 2008.

8. Rezaei N, Aghamohammadi A, Notarangelo LD, Primary immunodeficiency diseases : definition, diagnosis, and management. 2017.

9. Aghamohammadi A, et al. Inborn errors of immunity: practical guide. Academic Press; 2021. https://www.elsevier.com/books/ inborn-errors-of-immunity/aghamohammadi/978-0-12-821028-4.

Publisher's Note Springer Nature remains neutral with regard to jurisdictional claims in published maps and institutional affiliations. 